\title{
Nano-particles for Cosmetic Use: Particle Sizing, Cytotoxicity Test, and Facial Gesture Monitoring Model
}

\author{
Preecha Yupapin $^{1^{*}}$ and Panida Suwandee ${ }^{2}$ \\ ${ }^{1}$ Multidisciplinary Research Center, Faculty of Science and Technology, Kasem Bundit University, Bangkok, Thailand \\ ${ }^{2}$ Bangkok Assay Office, Bangkok, Thailand
}

*Corresponding author: Preecha Yupapin, Multidisciplinary Research Center, Faculty of Science and Technology, Kasem Bundit University, Bangkok, 10250, Thailand, Tel: +6689445 2224; E-mail: preecha.yup@kbu.ac.th

Received date: September 02, 2016; Accepted date: September 22, 2016; Published date: October 15, 2016

Copyright: $\odot 2016$ Yupapin P, et al. This is an open-access article distributed under the terms of the Creative Commons Attribution License, which permits unrestricted use, distribution, and reproduction in any medium, provided the original author and source are credited.

\begin{abstract}
The use of gold and silver nano-particles has been confirmed and popularly used for cosmetic material ingredients, where the small $\mathrm{Ag}$ and Au nano-particle diameters have no toxic with human cells, especially, for facial cells, in which the nano-particle diameter range of few nanometers, for instant, the average Ag and Au's diameters are $3.63 \mathrm{~nm}$ and $1.33 \mathrm{~nm}$ respectively. In this work, three interesting nano-particles $\mathrm{Ag}$, Au and Platinum (Pt) that were prepared by the Bangkok Assay Office (BAO) laboratory, in which the safety concerns are tested in terms of human dermal fibroblast cells by the BIOTEC, NSTDA in Thailand. From the obtained results, the Pt nano-particles were successfully prepared for the first time, where the sizes were ranged between 50 to $60 \mathrm{~nm}$. All prepared nanoparticles were tested and the human cell safety was seen without any toxic, which leads to being useful for the medical, healthcare and cosmetic applications, which was focused on the use of platinum nano-particles for the facial cosmetic material ingredient, where there is no evidence of human cells effect, which is confirmed by the BIOTEC, National Science and Technology Development (NSTDA), Thailand. In addition, the facial gesture model is proposed for the use of facial muscle monitoring that can be observed relatively to the change in facial cells, which is useful for further developments after the treatment, which is discussed in details.
\end{abstract}

Keywords: Cosmetic material; Cosmetic ingredient; Cosmetic treatment and monitoring; Nano-cosmetics

\section{Introduction}

Nano-particle for medicine and health has been widely used in various applications [1-5], where firstly silver can be used for natural antibiotic, cold, flu infection prevention, anti-inflammatory, boost the immune system, reduction in bodily toxins, more energy, vitality, vigor, relaxation, faster healing. Secondly, gold can be used for treatment in pain and swelling arthritis, sedative properties, reduce size of tumors, alleviate pain, improve appetite and digestion, increase weight and strength, enhance brain function, anti-inflammation, anti-oxidant, reactive oxygen species (ROS) scavenger and dehydrogenation, and finally, platinum can be used for enhances mental acuity, supports healthy generation of the heart tissue, thymus and the entire endocrine system, increases creativity, increases mental focus and concentration, promote lucid dreaming/mental clarity/meditative sates, promotes improve memory, support DNA repair, increase libido in both males and females, platinum is an antidepressant, restorative properties. Recently, nano-particles have also been involved in many areas of applications, where the wide use of them are seen [6]. Generally, nanoparticles are the compound materials, where the extraction (preparation) techniques are required, from which the fundamental particle size is formed and obtained, which can be suitable for various applications [7-10].

The use of nano-particles in cosmetics has shown the very interesting aspect, where the useful features of nano-particles such as $\mathrm{Ag}, \mathrm{Au}$ and $\mathrm{Pt}$, can be realized and useful for the value added business [11-19], in which the use of nano-particles for cosmetic has also been popularly seen and applied as the cosmetic materials and ingredient for a decade. Since the nano-particles such as silver, gold, and platinum have already been used in cosmetics, from which, there are two of them namely gold and platinum nano-particle have shown the interesting functions in cosmetics for such as cells enhancement, healing, and cancer treatment. However, the safety concerns have also been the important issue and investigated, where the interesting results are confirmed [20-22], from which the cosmetic used materials' cytotoxicity and safety have been investigated and discussed.

In this paper, the use of the practical data works that have found the very useful results described, which is about the use of nano-particles to mix into the cosmetic material ingredients, which is believed that the platinum nano-particle has the same property as Ag and Au. But it is better in the sense that it is more stabilized and better media that help to transmit neural signal to the cells. The results of the study consist of the nano-particle sizes were performed by NANOTEC, while the cytotoxicity was performed by BIOTEC, NSTDA in Thailand. The test result is about cytotoxin to see the reaction of human cells on platinum nano-particles, which can be concluded that the increasing use of gold and platinum for cosmetic ingredients (mainly focus on platinum) can be introduced. The discussion of the technique that can be used to monitor the facial cells related to the facial muscle function, which is useful for after cosmetic treatment is included.

\section{Methodology}

In this section, the interested nano-particles were prepared by BAO using the polyethylene glycol (PEG) technique [23] and the particle sizing and cytotoxicity were performed. There were three samples prepared by the Bangkok Assay Office laboratory, from the test of 
nano-particle sizes and cytotoxicity were performed by the NANOTEC and BIOTEC, NSTDA, Thailand, respectively. However, the standard size of the other two nano-particles Ag and Au are also given for useful discussion, whereas most of them are within the standard sizes, especially, the results of test samples are as shown in Figures 1a-1c. The tested nano-particle sizes of $\mathrm{Ag}$, $\mathrm{Au}$ and $\mathrm{Pt}$ are 3.63, 1.33, and $50 \mathrm{~nm}$ respectively, the commercial ones are $5 \mathrm{~nm}$ and $10 \mathrm{~nm}$ for gold and silver respectively.

\section{Results}

\section{Particle sizing}

Nano-particles were synthesized by BAO laboratory, where the Ag and $\mathrm{Au}$ nano-particles were synthesized by the reduction of particles ion precursors in solution with a stabilizing or capping agent to form colloidal nano-particles. All nano-particles were presented in the liquid forms. The particle sizing was processed as following details; (1) Use the Atomic Force Microscopy SEIKO Instrument Model SPA 400, (2) Analysis Mode: DFM (Dynamic Force Microscope) with the scan areas of 5 and 1.5 micrometer square, with $1 \mathrm{~Hz}$ scan speed, (3) Analysis Needle: NT-MDT Model HA-NC ETHALON, which force constant was $2.8 \mathrm{~N} . \mathrm{m}-1$, the resonant frequency was $100 \mathrm{KHz},(4)$ room temperature was 24.5 C, Humidity $50 \%$, (5) Sample preparation by (i) Dilute the sample with 1: 100 Deionization Water Mixture, (ii) Sample were sonicated in the sonicate bath for 15 minutes, (iii) Sample dropped on a mica plate for drying at room temperature, 30 minutes. Results are obtained as shown in Figures 1a-1c.

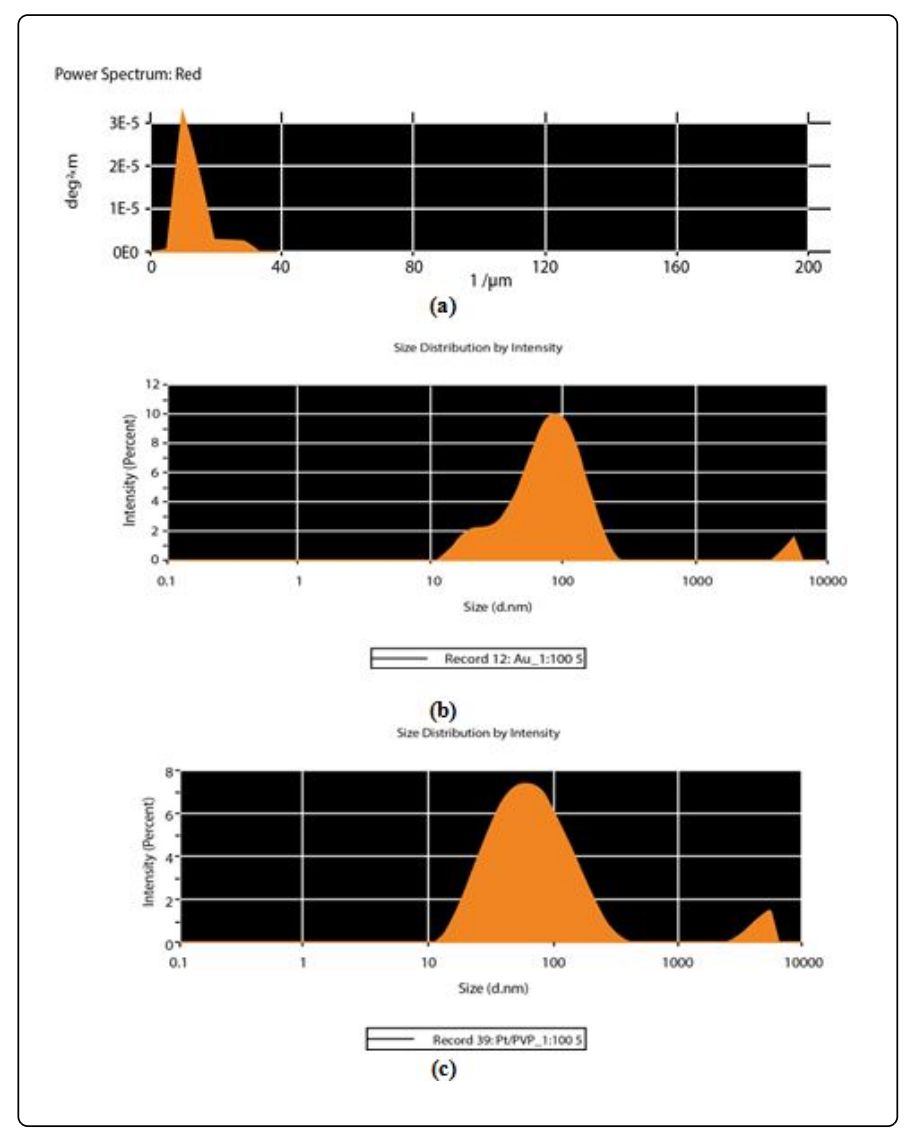

Figure 1: The schematic of nano-particle sizing measurements performed by NANOTEC Lab, NSTDA. The average diameters are (a) Ag with a diameter of $3.63 \mathrm{~nm}$, (b) Au with a diameter of 1.33 $\mathrm{nm}$ and (c) Pt with a diameter of $50 \mathrm{~nm}$.

\section{Cytotoxicity test}

The completed cytotoxicity test of $\mathrm{Ag}, \mathrm{Au}$, and $\mathrm{Pt}$, were performed by BIOTEC, NSTDA, Thailand using the published standard methods (BS-EN30993-5 and ISO10993-5) using human dermal fibroblast cell lines [24]. The cells were exposed to the sample for a period of 24 hours over the concentration range of $10-0.078 \%$. The results were shown by \% survival of cell at each concentration compared to the controlled IC50 values. The results of all samples were limited to the test condition, where there was no further extrapolation inferred. The samples were then serially diluted in the culture medium of cells at a ratio of $1: 2$ giving 8 concentrations of $10,5,2.5,1.25,0.625,0.3125$, 0.156 and $0.78 \%$. The target cells were human dermal.

Cells culture: The target cells were human dermal fibroblast cells. The cells were grown in Dulbecco's Modified Eagle's Medium (DMEM) supplemented with $10 \%$ fetal bovine serum, 2 ml-glutamine, 100 unit $/ \mathrm{ml}$ penicillin and $100 \mathrm{microgram} / \mathrm{ml}$ streptomycin. The cells were incubated at $37^{\circ} \mathrm{C}$ in a fully humidified, $5 \% \mathrm{CO}_{2}$ : atmosphere.

MTT cytotoxicity test: This assay is the modified version of conventional direct and indirect contact tests conformed to the published standard methods (BS-EN30993-5 and ISO10993-5). The MTT assay [25] is a tetrazolium dye based colorimetric micro-titration assay. Metabolism-competent cells are able to metabolize the tetrazolium (yellow) to the formation (blue); this color change is measured spectrophotometrically with the plate reader, which is assumed cells that are metabolically deficient will not survive, thus the MTT assay is also an indirect measurement of cell viability. The cells were seeded in a 96-well plate at a density of 10,000 cells/wells and incubated for 48 hours. The test samples were removed from the cell cultures and the cells were pre-incubated for a further 24 hours in fresh medium and then tested with MTT assay.

Briefly, $50 \mu \mathrm{l}$ of MTT in PBS at $5 \mathrm{mg} / \mathrm{ml}$ was added to the medium in each well and the cells were incubated for 4 hours. Medium and MTT were then aspirated from the well, and formazan solubilized with $200 \mu \mathrm{l}$ of DMSO and $25 \mu \mathrm{l}$ of Sorensen's Glycine buffer, $\mathrm{pH}$ 10.5. The optical density was read with the micro-plate reader (Molecular Device) at a wavelength of $570 \mathrm{~nm}$. The average of 4 wells was used to determine the mean of each point. The data was analyzed with the SoftMax program (Molecular Device) to determine the IC50 for each toxin sample, where a dose-response curve was derived from 8 concentrations in the test range using 4 wells per concentration. Results of toxic compounds are expressed as the concentration of sample required to kill 50\% (IC50) of the cells compared to controls.

The cytotoxicity profiles of $\mathrm{Au}, \mathrm{Ag}$, and $\mathrm{Pt}$, showed the percent of survival of human dermal fibroblast cells over the test concentration of $10-00.078 \%$. The results show that the Ag, Au, and Pt nano-particles were not cytotoxic to the human dermal fibroblast over the test range of $10-00.078 \%(\mathrm{v} / \mathrm{v})$. However, in the past studied, where mice injected with platinum nano-particles of less than $1 \mathrm{~nm}$ size developed symptoms of liver damage while mice injected with $15 \mathrm{~nm}$ platinum nano-particles did not [25]. In another study, mice that received a 
single injection of platinum nano-particles of less than $1 \mathrm{~nm}$ size developed necrosis of tubular epithelial cells and urinary casts in the kidney, while mice repeatedly injected with $8 \mathrm{~nm}$ platinum nanoparticles did not [26]. In yet another study, human cells exposed to platinum nan-particles $\sim 5-8 \mathrm{~nm}$ in size experienced DNA damage [27]. In this study, the platinum nano-particle diameter is $50-60 \mathrm{~nm}$, in which there is no evidence of using the platinum nano-particle diameter larger than the above data seen, especially for human facial cosmetic use.

\section{Further application feasibility}

This work was performed by the BAO laboratory, where the required nanoparticle sizes were obtained, the cytoxicity of those particles were also tested and saved. The company has planned to use such particles as the cosmetic material ingredients, from which the cosmetic material can be improved by using the proposed measurement, which will be discussed in the following details. This is the in-vivo test, where the contact between the sensing device and face skin can be introduced the change in sensing unit optical path difference, which will be detected and rerated to the change in muscle movements, which can be patterned and classified for the use of face healthcare improvement. The facial gesture pattern recognition can be patterned and stored by the technique that has proposed by Yothapakdee et al. [28-34], which is useful for cosmetic material ingredient use, where the before and after cosmetic treatments can be monitored and evaluated for the required improvements. Because the face is a communication channel with non-verbal language through the process of facial expressions, gestures and emotions, so, if the biomedical characteristics of the face can be monitored and collected to have been extremely useful for research and technological development of medical science and more. They have designed and proposed system for detecting the change of signals that occur on the face, which is characteristic of biological signals by comparing the difference in the level of force used for the facial gesture. The signal data of the facial gesture patterns is obtained through the detection of all the optical muscle sensing systems. The different types of facial gesture are the mechanism of muscle contraction and relaxation of the facial expression muscles, such as the orbicularis oculi muscle, corrugator supercilii muscle, levatorpalpebrae superioris and so on. In principle, the optical muscle sensor is assumed to have been attached to the mask or another device, which can be used to cover their faces, as shown in Figure 2 (1), where each of sensors is placed on the thin plastic mask in various positions, is used to measure signal patterns of change after the contraction and relaxation of facial muscles to facial gesture, as shown in Figure 2 (2), which is known as the muscle distributed sensing system. Such a system has been devised and modified on the optical muscle sensing system, which based on a comparison of the wavelength shift due to the change of the optical path length, which is caused by the change of facial gesture patterns. The changes affecting each sensor are converted to the degree of the force, which was introduced by the contraction and relaxation of muscles through the process of the optical muscle sensing system as shown in Figure 2 (3), where the important facial information can be detected by the optical muscle sensing system through the degree of force to be used for the contractile and relaxed mechanism of the muscle fibers to the facial gestures, which is, of course, related to the facial cell functions. In Figure 2 (4), these data signals are extremely useful to medical practitioners who will use them in the process of diagnosis and evaluate the feasibility of performing cosmetic treatment monitoring in the next step.

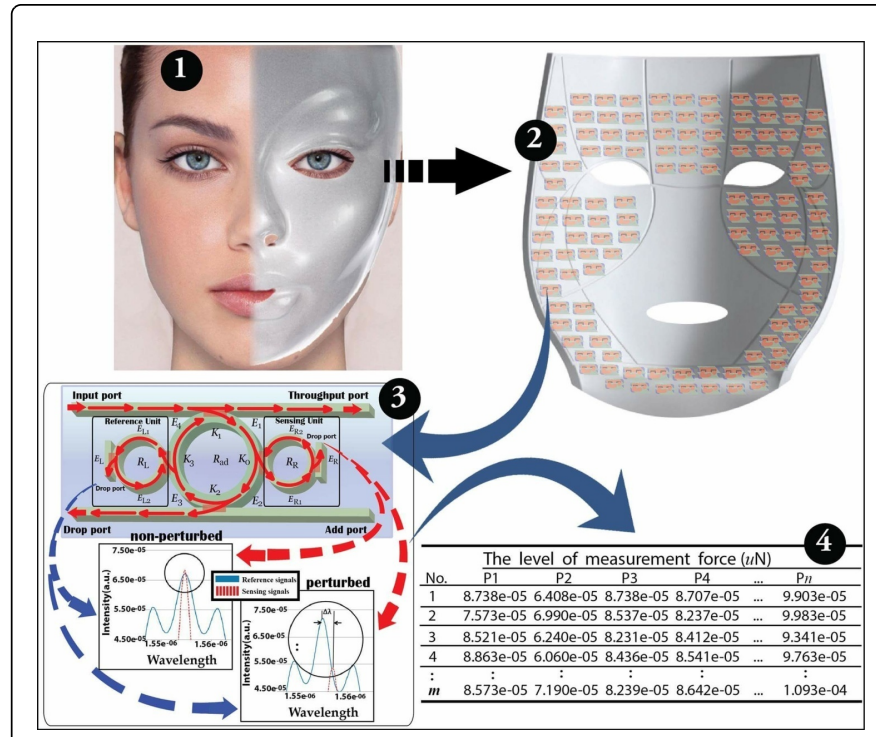

Figure 2: The muscle distributed sensing system presenting (1) the front of cosmetic treatment monitoring, (2) the inside of the mask and muscle distributed sensor, (3) the optical muscle sensing system, and (4) the level of measurement force.

\section{Conclusion}

This paper has reported the interesting aspect of using nanoparticles for cosmetic material ingredients, in which the major concerns are the particle cytotoxicity and cell healing and enhancement, especially, facial cells, where in addition the technique of facial cells monitoring using the micro-sensing system is also discussed. Gold is assumed to enhance human skin through the nervous system and endocrines system, since human brain communication process and executed by using electrical and chemical signal to and from the nervous system. The cosmetic materials have been dynamically developed in either for cells enhancement and healing since the nano-particles adopted within the cosmetic material ingredients. In this paper, the comparison of nano-particles in terms of particle size and cytotoxicity on human cells is investigated and presented, where the samples were silver, gold and platinum nanoparticles that were prepared by the Bangkok Assay Office laboratory. The interesting results were obtained and reported by the National Science and Technology Development (NSTDA), Thailand that they can be suitable for cosmetic materials and ingredients usages. The focus material within the cosmetic ingredient in this study is the platinum nano-particles, where the useful data in terms of physical and chemical seen. The product formulations and ingredients, toxicological studies of cosmetic and monitoring technique are also presented, especially for facial cosmetic are discussed, in which the facial gesture monitoring technique will be included, from which the pattern of facial muscle grid will be stored, which can be compared between before and after cosmetic treatments and stored by the facial gesture pattern recognitions. Regarding to the very good function of platinum particle with human cells, therefore the $\mathrm{BAO}$ is aiming to mix the $\mathrm{Pt}$ nano-particles within their cosmetic products after the confirmation of non-toxicity concern in the near future. 


\section{Acknowledgment}

The authors would like to give the acknowledgment to Bangkok Assay Office Laboratory, Multidisciplinary Research Center, Kasem Bundit University, Bangkok 10250 and the National Science and Technology Development (NSTDA), Thailand for the research facilities. We would also like to acknowledge to the Ton Duc Thang University, Ho Chi Minh City, Vietnam for the manuscript editing facilities.

\section{References}

1. Silpa Raj, Shoma Jose, Sumod US, Sabitha M (2012) Nanotechnology in cosmetics: Opportunities and challenge. J Pharm Bioallied Sci 4: 186-193.

2. Katie Anderson (2013) Assessing use of gold nanoparticles. Cosmetics \& Toiletries.

3. Atiyeh BS, Costagliola M, Hayek SN, Dibo SA (2007) "Effect of silver on burn wound infection control and healing: review of the literature". Burns 33: $139-148$.

4. Wallace DR (2015) Nanotoxicology and Metalloestrogens: Possible Involvement in Breast Cancer. Toxics 3: 390-413.

5. Guan Y, Emiel JM, Hensen (2009) Ethanol dehydrogenation by gold catalysts: The effect of the gold particle size and the presence of oxygen. Applied Catalysis: A General 361: 49-56.

6. Taylor R, Coulombe S, Otanicar T, Phelan P, Andrey G, et al. (2013) Small particles, big impacts: A review of the diverse applications of nanofluids. J Appl Phys 113: 011301.

7. Liu W, Greytak AB, Lee J, Wong CR, Park J, et al. (2010) Compact biocompatible quantum dots via RAFT-mediated synthesis of imidazolebased random copolymer ligand. J Am Chem Soc 132: 472-483.

8. Reiss G, Hutten A (2010) Magnetic Nano-particles. In Sattler, Klaus D. Handbook of Nanophysics: Nanoparticles and Quantum Dots. CRC Press. pp: 2-1.ISBN 9781420075458.

9. Howarth M, Liu W, Puthenveetil S, Zheng Y, Marshall LF, et al. (2008) Monovalent, reduced-size quantum dots for imaging receptors on living cells. Nature Methods 5: 397-399.

10. Yupapin P, Suwandee S (2015) Drug Targeting Model of Composite GoldTourmaline for Cells Enhancing Applications. Nano Biomed Eng 7: 38-46.

11. Suwandee S, Yupapin PP (2014) Gold Nano-particles Separation and Storage for Cosmetics, Healthcare and Beauty with Safety Usage. Life Science Journal 11: 1225-1229.

12. Shibata T, Yoshikawa R, Ichihashi M (2015) The Novel Therapy for Vitilogo Vulgaris: Topical use of Cosmetic Cream of Platinumnanoparticles and Palladium Nanoparticles which show Strong Catalase Like Activity. Pigmentary Disorders 2: 184.

13. Suwandee S, Yupapin PP (2014) Gemstone Property Studies for Minerals Based Cosmetics and Beauty Applications. Life Sci Journal 11: 871-873.

14. Martin R, Menchon C, Apostolova N, Victor M, Alvaro M, et al. (2010) Nano-Jewels in Biology. Gold and Platinum on Diamond Nanoparticles as Antioxidant Systems Against Cellular Oxidative Stress. ACS Nano 4: 6957-6965.

15. Gajbhiye S, Sakharwade S (2016) Silver Nanoparticles in Cosmetics. Journal of Cosmetics, Dermatological Sciences and Applications 6: 48-53.

16. Filon FL, Crosera M, Adami G, Bovenzi M, Rossi F, et al. (2011) Human skin penetration of gold nanoparticles through intact and damaged skin. Nanotoxicology 5: 493-501.
17. Ramamurthy $\mathrm{CH}$, Padma M, samadanam ID, Mareeswaran R, Suyavaran A, et al. (2013) The extra cellular synthesis of gold and silver nanoparticles and their free radical scavenging and antibacterial properties. Colloids Surf B Biointerfaces 102: 808-815.

18. Cosmetic compositions comprising nano-particles and processes for using the same, US Patent No: US 20030064086 A1

19. Aziz MS, Suwanpayak N, Jalil MA, Jomtarak R, Saktioto T, et al. (2011) Gold nanoparticle trapping and delivery for therapeutic applications. Int J Nanomedicine 7: 11-17.

20. Nnorom IC, Igwe JC, Oji-Nnorom CG (2005) Trace metal contents of facial (make-up) cosmetics commonly used in Nigeria. Afr. J. Biotechnol 4: 1133-1138.

21. Nohynek GJ, Antignac E, Re T, Toutain H (2010) Safety assessment of personal care products/cosmetics and their ingredients. Toxicol Appl Pharmacol 243: 239-259.

22. Loretz LJ, Api AM, Babcock L, Barraj LM, Burdick J, et al. (2008) Exposure data for cosmetic products: facial cleanser, hair conditioner, and eye shadow. Food Chem Toxicol 46: 1516-1524.

23. Li N, Zhao P, Astruc D (2014) Anisotropic Gold Nanoparticles: Synthesis, Properties, Applications, and Toxicity. Angew Chem Int Ed Engl 53: 1756-1789.

24. Locatelli E, Comes Franchini M (2012) Biodegradable PLGA-b-PEG polymeric nano-particles: synthesis, properties, and nanomedical applications as drug delivery system. Nanopart Res 14: 1316.

25. Yamagishi Y, Watari A, Hayata Y, Li X, Kondoh M, et al.(2013) Hepatotoxicity of sub-nanosized platinum particles in mice. Pharmazie 68: 178-182.

26. Plumb JA, Milroy R, Kaye SB (1989) Effects of the pH Dependence of 3(4, 5-Dimethylthiazo;-2-yl)-2, 5-Diphenyltetrazolium Bromide-Formazan Absorption on Chemosesitivity by a Novel Tetrazolium based Assay. Cancer Res 49: 4435-4440.

27. Yamagishi Y, Watari A, Hayata Y, Li X, Kondoh M, et al. (2013) Acute and chronic nephrotoxicity of platinum nanoparticles in mice. Nanoscale Res Lett 8: 395.

28. Asharani PV, Ng X, Hande MP, Valiyaveettil S (2010) DNA damage and p53-mediated growth arrest in human cells treated with platinum nanoparticles. Nanomedicine 5: 51-64.

29. Yothapakdee K, Yupapin PP, Tamee K (2016) Facial Gesture Measurement using Optical Muscle Sensing System. Nano Biomed Eng 7: 169-179.

30. Hamedi M, Salleh SH, Tan TS, Ismail K, Ali J, et al. (2011) Human facial neural activities and gesture recognition for machine-interfacing applications. Int J Nanomedicine 6: 3461-3472.

31. Chou JK, Yang CK, Gong SD (2012) Face-off: Automatic Alteration of Facial Features. Multimed Tools Appl 56: 569-596.

32. Park DM (2015) Total Facelift: Forehead Lift, Midface Lift, and Neck Lift. Arch Plast Surg 42: 111-125.

33. Jaafar A, Chornenky VI (2005) Apparatus and method for reducing subcutaneous fat deposits, virtual face lift and body sculpturing by electroporation. U.S. Patent No. 6,892,099.

34. Uomwech K, Sarapat K, Yupapin PP (2010) Dynamic modulated Gaussian pulse propagation within the double PANDA ring resonator system. Microw Opt Technol Lett 521: 1818-1821.

35. Yothapakdee K, Yupapin P (2016) Face Gesture Pattern Recognition using Muscle Distributed Sensor for Face Off Recovery. Journal of Biosensors \& Bioelectronics 7 in press. 